\title{
SISTEM INFORMASI HELPDESK TICKETING DI PT TUNAS ARTHA GARDATAMA
}

\author{
Riky Siswanto $^{1}$, Arif Susanto ${ }^{2}$, Eddy Saputra ${ }^{3}$ \\ Program Studi Informatika, Fakultas Teknik dan Ilmu Komputer, Universitas Indraprasta PGRI \\ Jalan Raya Tengah No 80, Kelurahan Gedong, Pasar Rebo, Jakarta Timur \\ rikymana@gmail.com ${ }^{1}$, arif_susanto3@gmail.com ${ }^{2}$, saputra2578@gmail.com ${ }^{3}$
}

\begin{abstract}
Abstrak
PT. Tunas Artha Gardatama adalah perusahaan yang besar dan memiliki cabang hampir diseluruh wilayah Indonesia, dengan jumlah karyawan yang banyak serta tanggung jawab yang besar, demi menjawab kebutuhan client dan aktivitas pekerjaan maka sudah sewajarnya penggunaan Teknologi Informasi diperlukan untuk menunjang kebutuhan dalam menjalankan usahanya. Akan tetapi dalam menjalankan aktivitas usaha juga terdapat permasalahan, salah satunya adalah permasalahan dalam penanganan kerusakan perangkat komputer yang dapat menghambat proses aktivitas kerja, sampai permasalahan tersebut diselesaikan aktivitas pekerjaan akan tergangu, meskipun permasalahan dapat diselesaikan diperlukan juga pencatatan penanganan permasalahan yang berfungsi sebagai dokumentasi serta sebagai acuan jika terdapat permasalahan yang sama terjadi. Dalam pembuatan sistem informasi ini bertujuan untuk mempermudah user untuk melakukan pelaporan permasalahan, serta mempermudah teknisi dalam melakukan diagnosa untuk menangani permasalahan tersebut, selain itu juga dapat menjadi center point, helpdesk untuk menangani permasalahan perangkat komputer dan hal lain yang berhubungan dengannya. Dalam penelitian ini peneliti menggunakan metode Grounded research dimana penelitian berdasarkan fakta dan menggunakan analisis perbandingan dengan tujuan mengadakan generalisasi empiris menetapkan konsep, membuktikan teori, mengembangkan teori, pengumpulan dan analisi data yang merupakan sumber teori atau teori berdasarkan data. Sistem ini dirancang untuk mempermudah proses pelaporan kerusakan perangkat komputer dan penangananya.
\end{abstract}

Kata kunci: Sistem Informasi, Helpdesk, Ticketing, Teknologi, Komputer

\begin{abstract}
PT. Tunas Artha Gardatama is a large company and has branches in almost all parts of Indonesia, with a large number of employees and big responsibilities. In order to respond to clients ' needs and job activities, the use of information technology is required to support their business needs. But in conducting business activities there are also problems, one of which is problem handling damage computer devices that impede the process of working until the problem has not resolved the work will be rolled. Although the problem has been solved, it is necessary to note the handling of problems that serve as documentation and reference if there is a similar problem. In making this information system aims to facilitate users to report problems, and facilitate the technician in conducting a diagnosis to handle the problem. In additions it can be a center point, helpdesk to handle the problems of computer devices and other things related to it. Researchers use the Grounded research Method in its research, where research-based facts and use comparative analysis with the aim of conducting empirical generalizations define concepts, prove theories, develop theories, collect and analyze data that is a source of theory or theory based on data. This system is designed to facilitate the process of reporting damage to computer devices and their handling.
\end{abstract}

Keywords: Information Systems, Helpdesk, Ticketing, Technology, Computer.

\section{PENDAHULUAN}

Perkembangan teknologi yang pesat dan kemudahan yang ditimbulkanya berdampak langsung terhadap semua aspek kehidupan, tanpa terkecuali aspek dunia usaha, disebuah organisasi perusahaan, dalam menjalakan usaha pemanfaatan teknologi informasi juga banyak digunakan dalam proses pekerjaan bahkan semua aktivitasnya menggunakan teknologi informasi. Teknologi informasi juga memiliki peranan yang sangat strategis dan signifikan dalam sebuah organisasi perusahaan, selain itu bagi perusahaan merupakan sebuah keharusan untuk mampu menerpakan dan menguasai secara teknis. 
Pemanfaatan teknologi informasi juga dapat digunakan sebagai sarana pengambilan keputusan dalam suatu permasalahan, dengan mengidentifikasi informasi-informasi yang telah didapatkan sebelumnya dimana informasi tersebut digunakan untuk menyelesaikan masalah dengan efisien. Menurut (Sutabri, 2012) sistem adalah kumpulan unsur-unsur yang bergabung menjadi satu kesatuan dan mempunyai tujuan yang sama, Unsur-unsur dalam sistem tersebut saling berhubungan satau sama lainuntuk memudahkan arus informasi agar dicapainya suatu tujuan Bersama. Didalam sistem terdapat unsur-unsur penggerak sehingga pengerak tersebut saling berinteraksi satu sama lain untuk mencapai tujuan yang diinginkan. Menurut (Sutabri, 2012) Informasi merupakan data yang sudah diolah yang ditunjukan untuk seseorang, organisasi ataupun siapa saja yang membutuhkan. Informasi akan berguna apabila yang membutuhkan informasi tersebut membutuhkan informasi tersebut.

Sebagai perusahaan yang terbilang cukup lama berdiri PT Tunas Artha Gardatama masih belum memanfaatkan sistem informasi didalam penanganan permasalahan perangkat komputer, oleh sebab itu proses pelaporan permasalahan dan penangananya masih belum maksimal. Selain itu informasi yang didapat dari laporan permasalahan juga sangat minim sehingga proses penangananya memerlukan waktu yang cukup lama. Karena tidak adanya penggunaan sistem informasi dalam masalah tersebut, informasi laporan penanganan yang diberikan kepada pihak manajer juga tidak ada, informasi perangkat yang mengalami kerusakan juga sangat minim, hal ini yang melatarbelakangi peneliti untuk melakukan penelitian dengan judul "Sistem Informasi Helpdesk Ticketing di PT. Tunas Artha Gardatama". Menurut (Hendini, 2016) Ticketing adalah sebuah karcis gangguan (atau disebut juga laporan masalah) yang digunakan dalam suatu organisasi untuk melacak deteksi, pelaporan, dan resolusi dari beberapa jenis masalah. Trouble sistem ticketing berasal dari manufaktur sebuah dasar sistem pelaporan kertas. Sekarang kebanyakan berbasis web dan terkait dengan hubungan manajemen pelanggan seperti call center atau $e$ business".

Tujuan utama dari penelitian ini adalah merancang dan membangun sebuah sistem yang dapat mengakomodir kebutuhan-kebutuhan informasi yang diperlukan. Manafaat dari penelitian ini yaitu menyediakan suatu media bagi user untuk melakukan laporan secara mendetail tentang kerusakan perangkat komputer, dan mempermudah teknisi dalam melakukan penanganan permasalahan yang telah dilaporkan, serta tersedianya informasi yang dibutuhkan untuk melakukan pelaporan penanganan permasalahan kepada manajer.

\section{PENELITIAN RELEVAN}

Sebagai acuan dalam penelitian peneliti juga merasa perlu mempelajari lebih dalam tentang apa yang akan diteliti, penelitian-penelitian yang sudah dilakukan terdulu menjadi reverensi peneliti agar isi dari penelitian ini lebih bermanfaat dan aktual, Adapun penelitian yang menjadi reverensi peneliti untuk mengangkat topik penelitian ini adalah sebagai berikut :

Penelitian oleh (Qoyyimah et al., 2012) yang berjudul "Rancang Bangun Helpdesk Ticketing System (Studi kasus : PT. Primus Indo Jaya)", mengemukakan bahwa dengan perancangan sistem yang ada terkontrolnya proses dalam memperbaiki keluhan Client internet PT. Primus Indojaya dan penanganan kerusakan hardware terkoordinasi dengan baik, pencatatan masalah dapat dilakukan secara sistematis, sehingga data aman dan akurat dengan tidak adanya data yang duplikasi.

Penelitian selanjutnya oleh (Irawan \& Nanda, 2017) yang berjudul "Rancang Bangun Aplikasi helpdesk Dengan Menggunakan Pendekatan Knowledge Management System Pada Seksi Teknisi PT. Indah Kiat Pulp \& Papper tbk". Mengemukakan bahwa perancangan system helpdesk sangat membantu dalam pendistribusian pengetahuan karyawan teknisi melalui system yang tersedia yang merekam setiap informasi berupa prosedur perbaikan fasilitas. 


\section{METODE PENELITIAN}

\section{Metode Penelitian Yang Digunakan}

Metode penelitian yang peneliti gunakan untuk mendapatkan informasi serta data-data yang diperlukan adalah menggunakan metode deskriptif dengan tujuan untuk mendapatkan data secara detail, mendalam, dan juga aktual.

\section{Metode Pengumpulan Data}

Metode pengumpulan data yang penulus lakukan utuk mendapatkan data dalam melakukan analisis yang akan digunakan untuk mengetahui permasalahan, berikut metode pengumpulan data yang peneliti lakukan:

1. Studi pustaka

Dengan membaca buku dan mengumpulkan data dari internet serta artikul yang berhubungan dengan penelitian.

2. Studi lapangan

a. Wawancara

Mewawancarai langsung orang yang terkait dengan penggunaan sistem.

b. Observasi

Pengamatan langsung yang dilakukan oleh peneliti terhadap obyek-obyek yang ada pada perusahaan atau instansi untuk medapatkan data-data yang diperlukan.

c. Penelitian yang sejenis

Metode pengumpulan data dengan membandingkan penelitian yang sejenis dengan judul penelitian "Rancang Bangun Helpdesk Ticketing System (Studi Kasus: PT. Primus Indojaya)".

\section{HASIL DAN PEMBAHASAN}

\section{Diagram Alir Data (DAD) Sistem Yang Diusulkan}

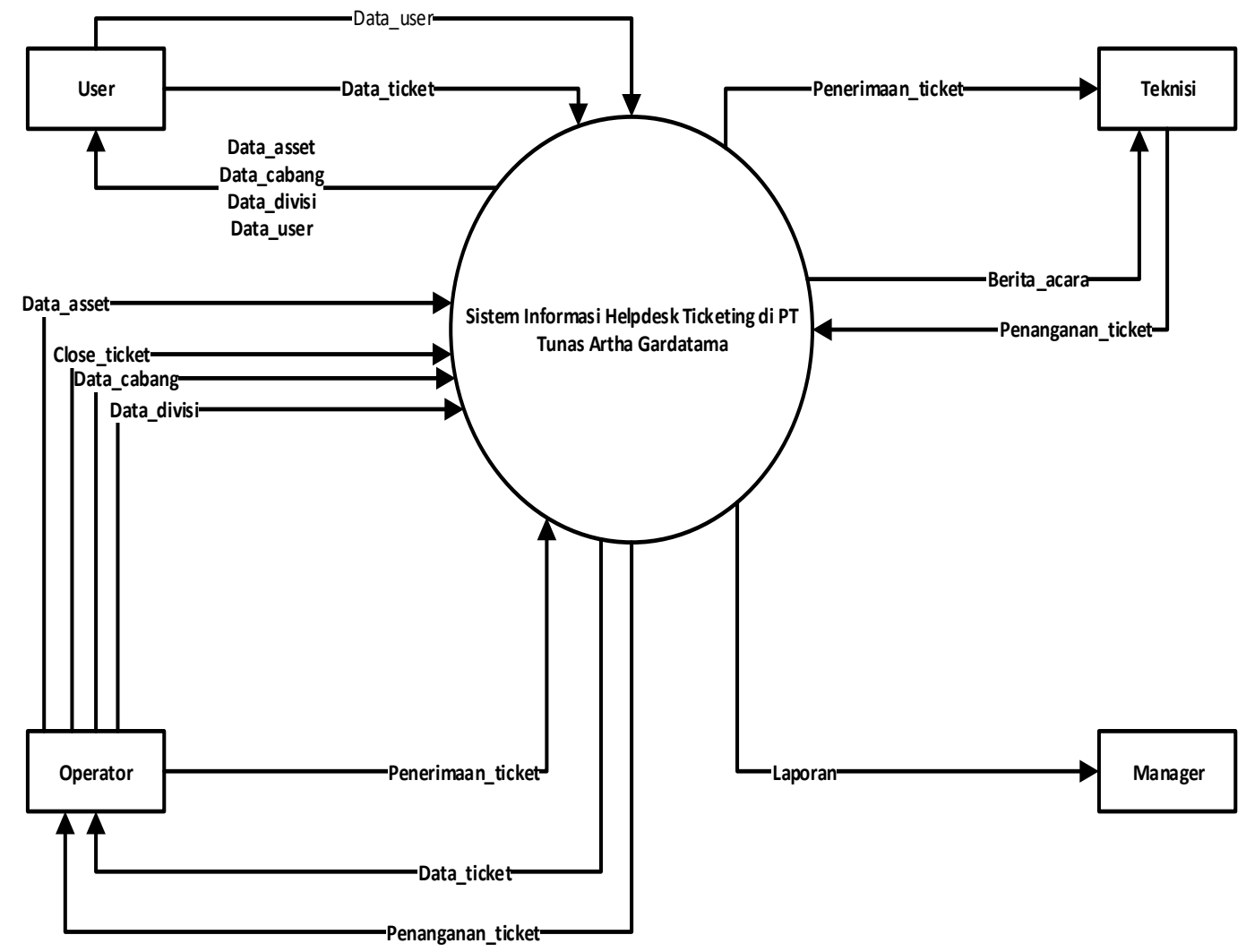

Gambar 1. Diagram Alir Data (DAD) Sistem Yang Diusulkan 
JRAMI (Jurnal Riset dan Aplikasi Mahasiswa Infarmatika)

Vol OI No Q3 Tahun 2020

e-ISSN : 2715-8756

Normalisasi Bentuk Ke-1 (1NF) Sistem Yang Diusulkan

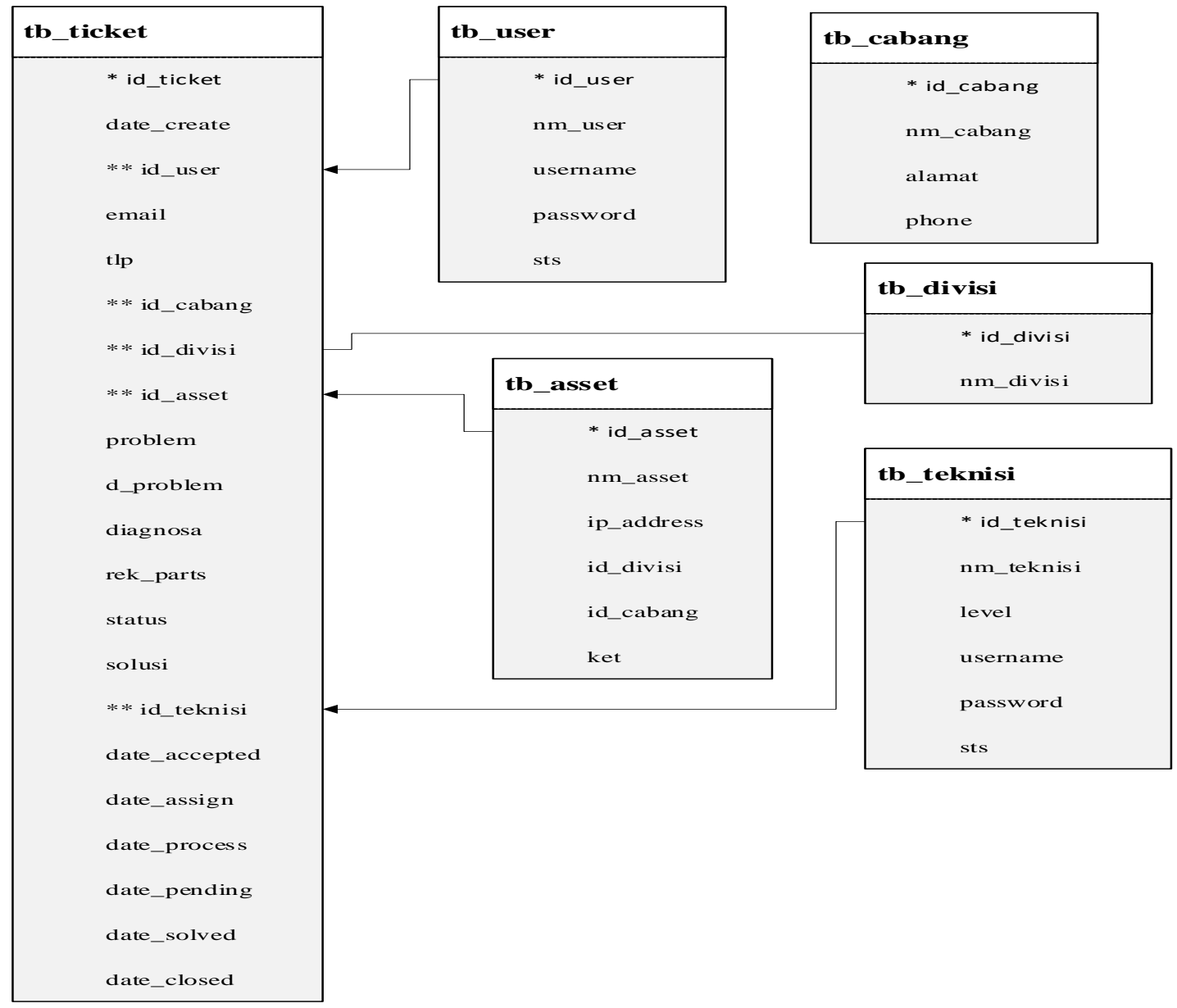

Gambar 2. Normalisasi Bentuk Ke-1 (1NF) Sistem Yang Diusulkan

\section{Tampilan Aplikasi}

IT HELPDESK

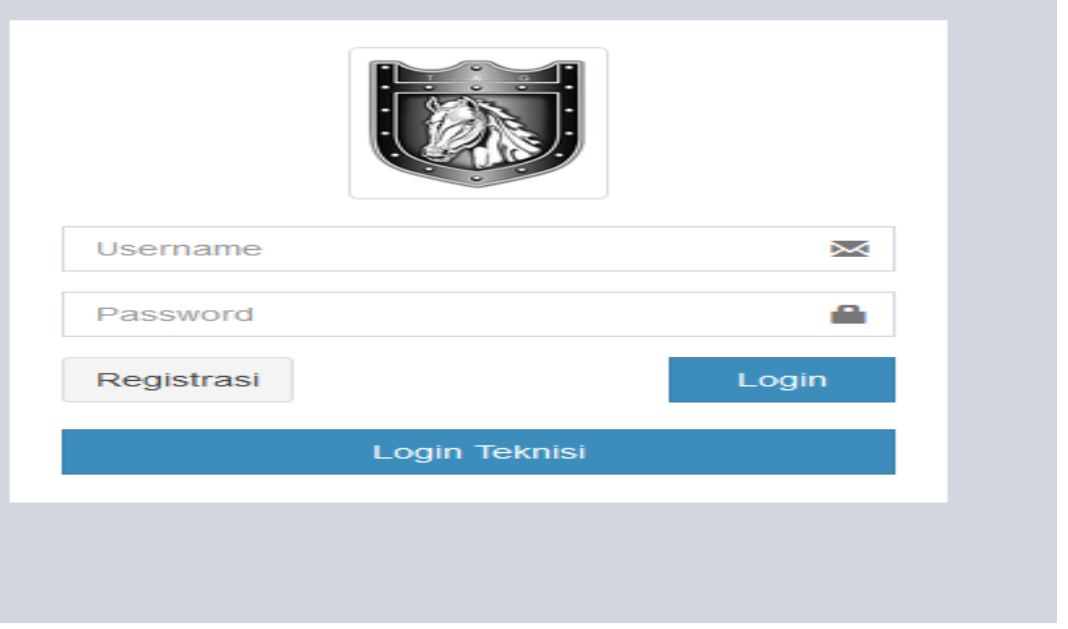

Gambar 3. Tampilan From Login 
Ini adalah tampilan halaman utama saat aplikasi diakses, terdapat form yang harus diisi oleh user yaitu username dan password, dimana username dan password telah dibuat sebelumnya.

\begin{tabular}{|c|c|c|c|}
\hline HelpdeskTAG & $\equiv$ & & $a$ \\
\hline $\begin{array}{l}\bullet \text { Orline } \\
\text { Man NaVightion }\end{array}$ & Dashboard & & at Home Dashboorr \\
\hline A Dashboard & BUAT TICKET & $\begin{array}{l}\text { UST PENGAUAAN } \\
\text { TICKET }\end{array}$ & \\
\hline
\end{tabular}

Gambar 4. Tampilan Menu Utama User

Setelah melakukan login user akan dialihkan pada menu dashboard yaitu menu utama setelah login

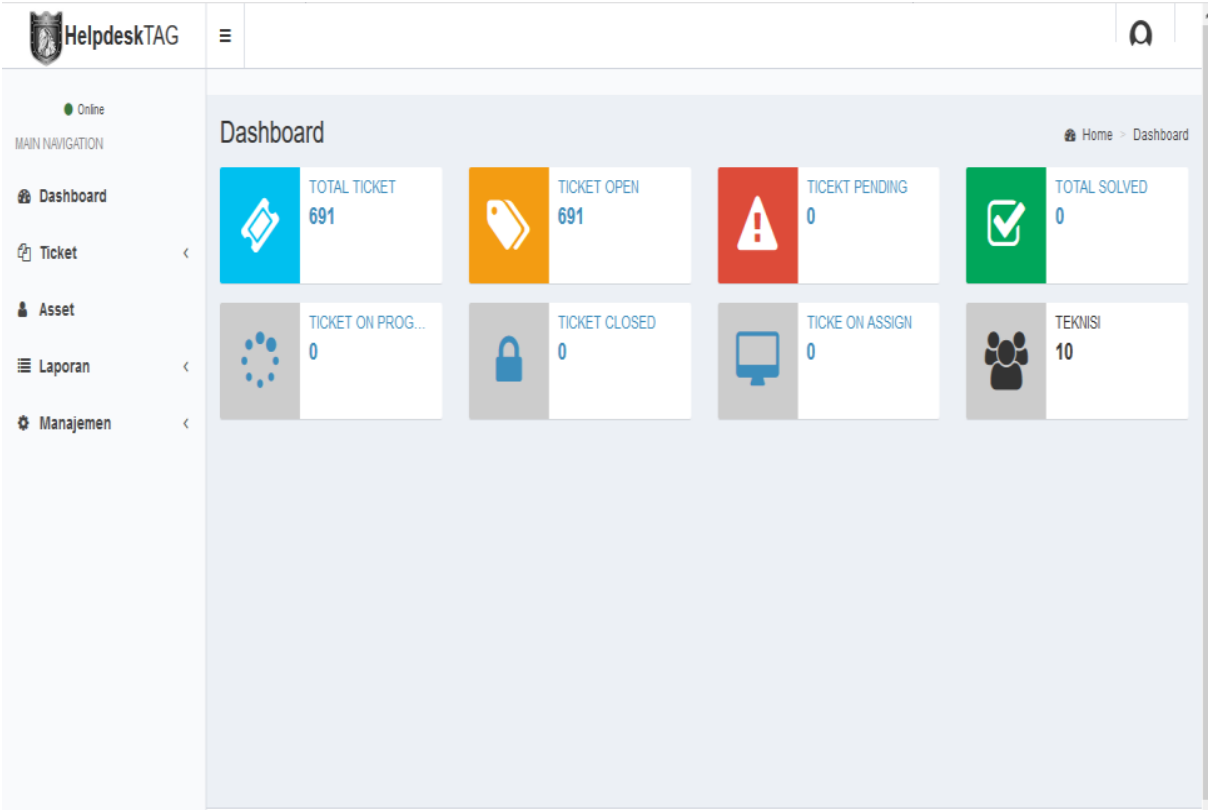

Gambar 5. Tampilan Menu Utama Teknisi

Gambar diatas adalah tampilan dashboard dari teknisi dimana terdapat menu yang lebih banyak daripada menu user 


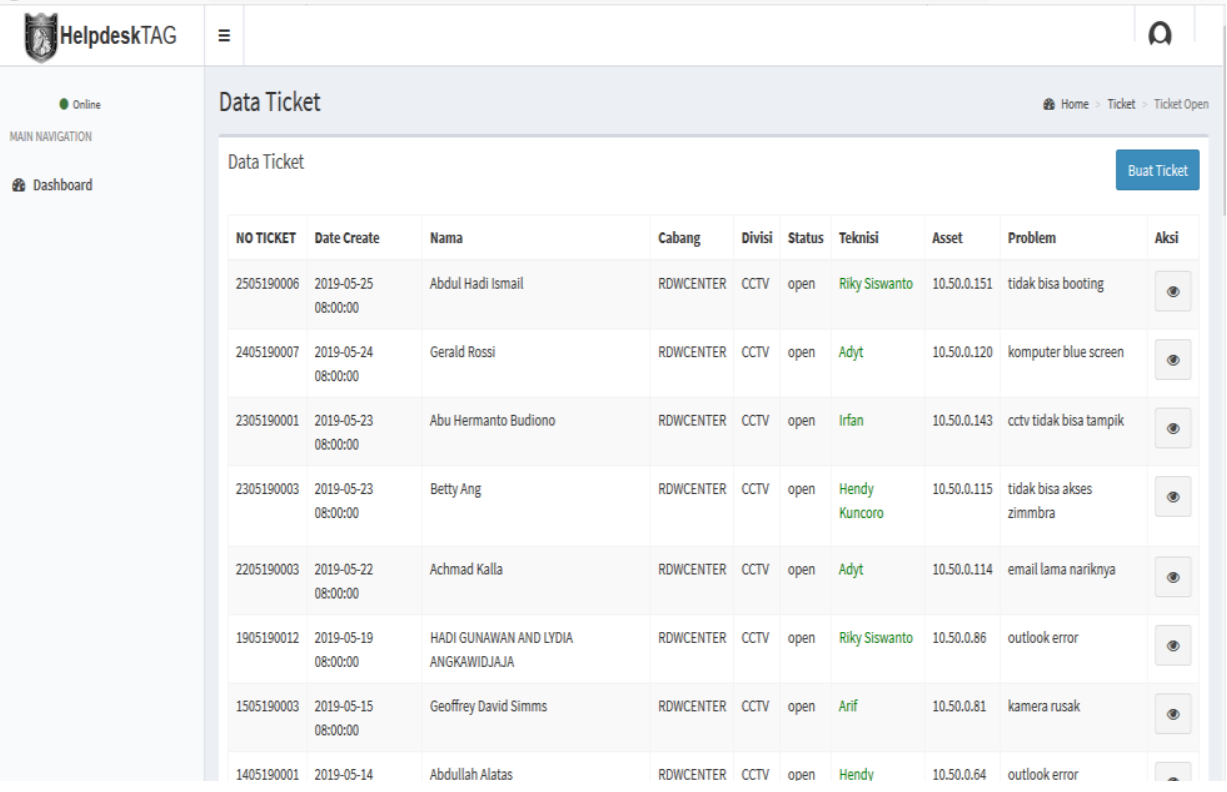

Gambar 6. Tampilan Data Ticket

Gambar diatas merupakan tampilan data ticket yang telah diajukan oleh user

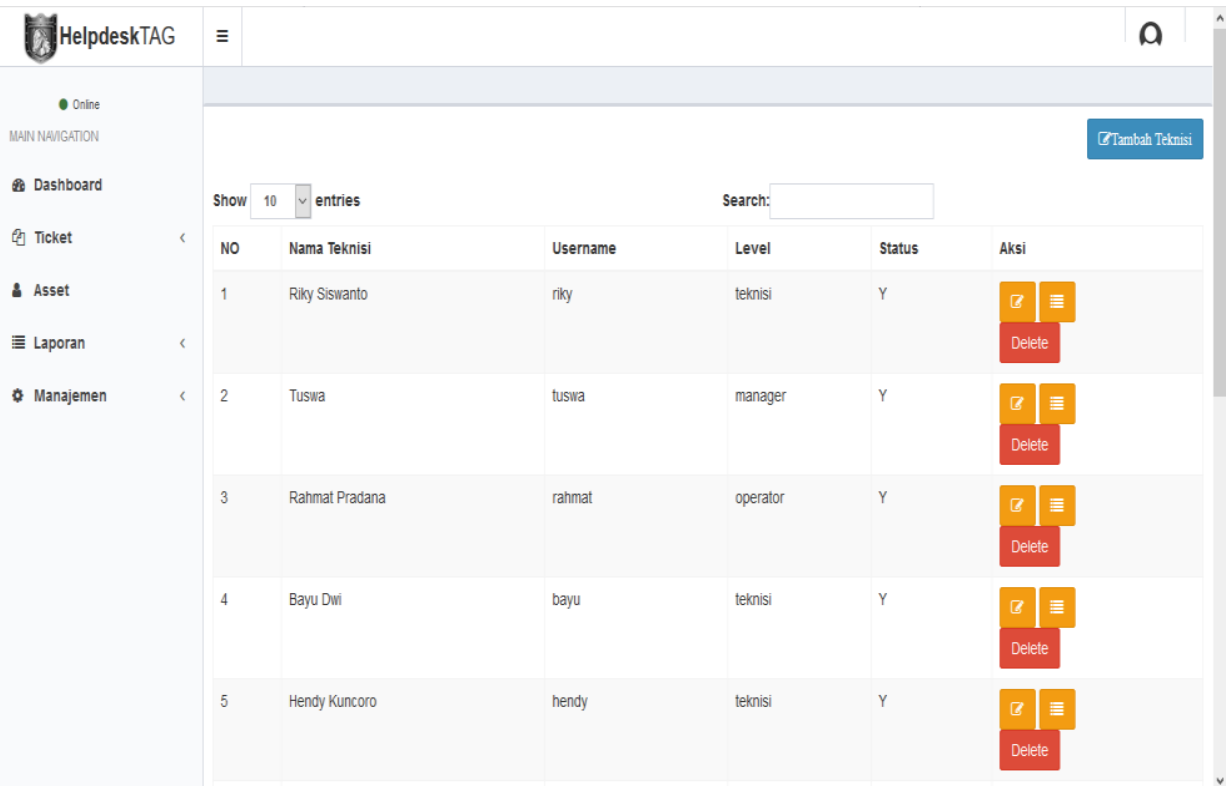

Gambar 7. Tampilan Data Teknisi

Tampilan diatas merupakan list dari teknisi yang bertugas dan terdapat didalam sistem

\section{SIMPULAN}

Dengan dibuatnya Sistem Informasi Helpdesk Ticketing, semua proses pengelolaan data penanganan problem perangkat yang dilakukan oleh IT tidak lagi dilakukan secata manual, proses pelaporan juga sudah terkomputerisasi dan dapat tersedia kapan saja saat dibutuhkan. Dengan adanya sistem ini diharapkan semua proses-proses yang terjadi lebih terstruktur serta mempermudah pengerjaan dan 
laporan, sehingga tidak terjadi kesalahan komunikasi antara user dan teknisi, kecepatan dan keakuratan juga membutuhkan partisipasi dari sipemakai sistem, terutama, terutama kemauan para pengguna yng memakai sistem ini sebagai alat untuk melakukan pelaporan masalah, peneliti menyimpulkan dengan adanya sistem ini semua aspek-aspek yang terkait dengan pelaporan dan penanganan akan menjadi lebih mudah karena tersedianya data yang dapat dijadikan sebagai acuan, berikut beberapa manfaat yang didapat dengan adanya sistem ini.

\section{DAFTAR PUSTAKA}

Hendini, A. (2016). Pemodelan UML Sistem Informasi Monitoring Penjualan dan Stok Barang. Khatulistiwa Inform, 2, $107-106$. Irawan, Agus.Nanda, K. S. (2017). Rancang Bangun Aplikasi helpdesk Dengan Menggunakan Pendekatan Knowledge Management System Pada Seksi Teknisi pt. Indah kiat pulp \& paper tbk. Jurnal ProTekInfo, 4, 6.

Manopo RI, Wowor H, L. (2016). Perancangan Aplikasi Help Desk Di UPT-TIK Unsrat. Tek Inform, 1, 8.

Qoyyimah, Hidayah, N. A., \& Fananie, Z. B. (2012). Rancang Bangun Helpdesk Ticketing System ( Studi Kasus : Pt . Primus Indojaya ). Jurnal Sistem Informasi, 5(1), 1-7.

Sutabri, T. (2012). Konsep Sistem Informasi. CV Andi Offset. 